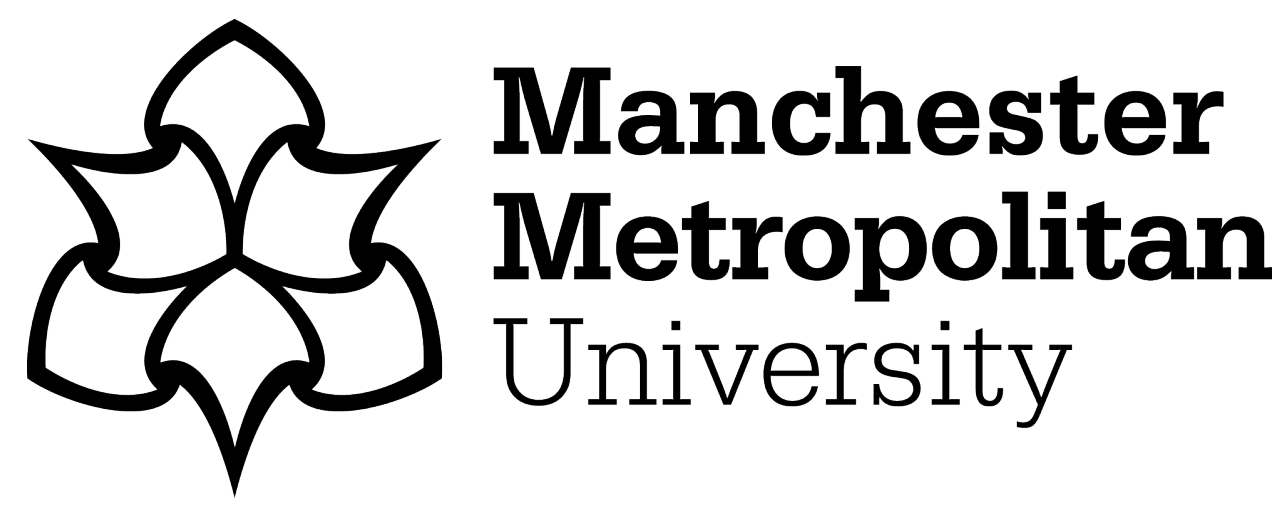

Jepegnanam, C, Bull, E ORCID logoORCID: https://orcid.org/0000-00029444-0597, Bansal, S, McCarthy, D, Booth, M, Purser, E, Makaka, T, Shapley, G, Cooper, J, Probert, J and Malpus, Z (2021) The role of the psychologist in the inpatient pain service: development and initial outcomes. British Journal of Pain, 15 (2). pp. 163-174. ISSN 2049-4637

Downloaded from: https://e-space.mmu.ac.uk/625991/

Version: Accepted Version

Publisher: Sage

DOI: https://doi.org/10.1177/2049463720926212

Please cite the published version 


\section{The Role of the Psychologist in the Inpatient Pain Service: Development and Initial Outcomes}

\section{Abstract}

This article describes the development and initial evaluation of introducing a psychologist role within an adult Inpatient Pain Service (IPS) in a large North West of England NHS Trust.

\section{Background:}

The role of a psychologist in the management of outpatient chronic pain has been well documented, but their role within the IPS is less well described and rarely evaluated. We describe the development of a psychologist role within the team and initial service evaluation outcomes.

\section{Methods:}

Following an initial needs assessment, a band 8c psychologist joined the IPS one day per week offering brief one-to-one psychological interventions to people struggling with acute or chronic pain in hospital referred by inpatient pain team. The psychologist had an indirect role offering training, supervision and support to members of the inpatient pain team. Regarding direct patient work, following psychometric screening for pain-related disability and distress, a Cognitive Behavioural Therapy (CBT) approach was applied including identifying unhelpful beliefs about pain, psychoeducation about acute and persistent pain, developing and sharing formulations, skills training including breathing and relaxation exercises and where appropriate, signposting onto an outpatient chronic pain services for further pain selfmanagement advice (e.g. Pain Management Programme (PMP). To explore the impact of this direct intervention, a prospective service evaluation with a controlled before and after design was conducted. This compared a) number of admissions and b) length of stay outcomes in the 12 months following psychometric screening for patients who received psychological input ( $n=34$, treatment group) and a sample who did not receive input because of discharge before intervention or non-availability of the psychologist e.g. annual leave ( $n=30$, control group). Demographic information and summaries of psychometric questionnaires were also analysed.

\section{Results:}

Of the sample of 64 patients, fifty were women, ages ranged from 18-80, 72\% reported being currently unemployed or off sick from work and on screening, 39\% and 48\% met criteria for severe depression and pain related anxiety respectively. Hospital admissions in the intervention group reduced significantly (by 60\%) in the 12 months following screening but increased (by $7 \%$ ) for the control group $[\mathrm{F}(1,62)=7.21, \mathrm{p}=.009]$. Days of stay in hospital reduced significantly more (by 84\%) in the intervention group than the control group (by $41 \%) \quad[F(1,62)=8.90$, $\mathrm{p}=.004]$. Illustrated case studies of brief psychological intervention with three people struggling with pain-related distress are presented.

\section{Conclusions:}

The psychologist became a valuable member of the multi-disciplinary IPS team, offering brief direct and indirect psychological interventions. Whilst a relatively small sample, our prospective 
service evaluation data suggest brief psychological intervention may contribute to reduced length of stay and hospital admissions for people experiencing pain-related distress in hospital.

\section{Keywords}

Pain; psychological distress; anxiety; depression; catastrophizing; psychological therapy; inpatient pain

\section{Background}

Pain is one of the main reasons why people seek healthcare ${ }^{1,2}$ and has been described as a highly prevalent problem within acute hospital settings, affecting up to $84 \%$ of inpatients 3 . Approximately $60 \%$ of patients experience severe pain postoperatively ${ }^{4}$. Pain experienced in hospital may also be linked to acute medical illness, trauma, non-surgical tests or procedures or represent an acute exacerbation of cancer pain or chronic non cancer pain ${ }^{5}$. Good quality acute pain management has been considered a fundamental human right ${ }^{6}$ and especially in the case of peri-operative pain, has been linked to a range of positive health outcomes and health care system benefits ${ }^{7,8}$.

Inpatient Pain Services (IPS), (also known as Acute Pain Services) were first conceived in the late $1980 s^{9}$ and early $1990 s^{10}$. In the UK the influential Royal College of Surgeons (RCOS) and Royal College of Anaesthetists (RCOA) report proposed that acute pain teams should manage acute pain after surgery, organise healthcare services, provide in-service training for medical and nursing staff, and conduct acute pain audit and research. Importantly, this advocated that a multidisciplinary approach 'including medical, nursing, psychological and pharmaceutical expertise is essential to the successful provision of Acute Pain Services'10 (p.28) Pain specialists have long recognised that pain is a complex biopsychosocial phenomenon, with psychosocial factors fundamental to the perception, experience and consequences of pain ${ }^{11,12}$.

Pain-related distress can cause exacerbation of pain via sympathetic arousal of the autonomic nervous system, which can, in turn be misinterpreted by patients as deterioration to their underlying medical condition, causing further pain-related distress, in a vicious circle ${ }^{13}$. Positively, psychological interventions are effective in reducing pain, disability, psychological distress and catastrophic thinking about pain ${ }^{14}$. Psychologically-based pain management approaches typically include techniques from Cognitive Behavioural Therapy (CBT) ${ }^{14}$ and Acceptance and Commitment Therapy (ACT) ${ }^{15}, 16$ for example to help correct any misunderstandings about causes of pain and provide psychoeducation about natural bodily stress reactions to pain. This approach utilises training in behavioural stress reduction, thought challenging and acceptance techniques, applying problem formulations, graded exposure, problem solving and goal setting. These techniques could be highly relevant for inpatients experiencing pain related distress.

For a minority of emergency inpatients, their admission will have been precipitated by a lifethreatening event. Some may experience acute safety fears for themselves or others and be involved with distressing police investigations; others may have symptoms of acute stress disorder, which, if left unrecognised, could precipitate the development of post-traumatic stress disorder (PTSD). PTSD and chronic pain often co-occur, and pain coping strategies and 
depressive symptoms are thought to partially mediate this relationship ${ }^{17}$. There is a need to recognise these complexities and offer treatment or appropriate referral to specialist mental health services in patients referred to the IPS.

The fear-avoidance model of pain is also relevant to the hospital setting: patterns of either movement and recovery or avoidance leading to disability may be crucially developed and reinforced through encounters with staff, fellow patients and relatives in hospital ${ }^{18}$. In surgical populations, preoperative and perioperative psychological states, such as depression, anxiety and pain catastrophising are key modifiable risk factors for surgical outcomes ${ }^{19,20}$. Those with psychological risk factors are more likely to experience severe acute postoperative pain, excessive opioid analgesic use in hospital and the development of Chronic Post-Surgical Pain (CPSP) which affects $20 \%$ of the surgical population ${ }^{21}$. People experiencing these difficulties also tend to have a longer length of hospital stay after surgery ${ }^{22,23}$. In one setting, Canada's Toronto General Hospital, a multidisciplinary team including psychologists have developed a Transitional Pain Service for people at risk of developing CPSP and pain disability. The service provides coordinated care preoperatively, postoperatively and post-discharge from hospital, strengthening optimism, problem focussed coping skills and self-efficacy with promising results 24 .

Aside from those experiencing surgery, chronic non-malignant pain is a major cause of disability, reduced quality of life, productivity and increased healthcare utilisation. Patients with chronic pain account for approximately $12-16 \%$ of emergency department visits with about $7 \%$ of patients presenting multiple times ${ }^{25}$. Research suggests that people with chronic pain seek inhospital treatment for a variety of reasons, including dissatisfaction with pain management or stress or anxiety related to social or vocational issues. It is often difficult to identify one clear cause of acute exacerbation of chronic pain, with psychological distress, sleep disturbances, disease progression, and complex medication use thought to be common underlying causes. Psychological treatments are found to be beneficial in these situations ${ }^{26}$. Many hospital admissions due to chronic pain flare-ups may be avoidable, but may carry a 'hidden' burden because patients are admitted under a variety of specialties ${ }^{27}$.

It is clear then that there is a major role for the practitioner psychologist as a core member of the IPS. With successive UK guidelines for IPSs ${ }^{28,29}$ their role has broadened to ensuring consistency and effectiveness of pain management for all inpatients. The roles, qualifications and supervision of practitioner psychologists working in pain management services have been further helpfully articulated in the UK Core Standards for Pain Management Services ${ }^{30}$. However, a recent audit pointed to wide variation in the composition, quality and consistency of IPSs across the $\mathrm{UK}^{31}$. One of the striking findings was that only $19 \%$ of services responding indicated that they had access to a psychologist. It was not clear how many, if any, included a dedicated psychologist within the team. In the UK, a small case series pointed to the potential costeffectiveness of psychologists as part of inpatient pain services ${ }^{32}$ but to our knowledge, no UK study had explored cost effectiveness with a larger group of patients.

\section{Aims of this article}

This article describes the development of the psychologist role within an Inpatient Pain Service in a large NHS Trust in Northern England. The inpatient Pain Service did not previously have a psychologist in the team and we were constantly aware of the need for complete bio-psychosocial management of patients with complex pain issues and the inability to deliver such an 
option. Many hours were spent with patients by pain consultants and specialist pain nurses with very little psychological training, trying to support the management of these patients. It was also observed that these patients not infrequently went home with high doses of opiates in spite of our best efforts. This article aims to firstly describe the development of the role of a psychologist, including a needs assessment conducted with patients and IPS team members, before presenting the results of an initial service evaluation comparing admission and length of stay outcome data prospectively for patients referred to the service who did vs. did not receive brief psychological input during their hospital stay. We present case studies illustrating a range of direct intervention work before exploring challenges and lessons learned, with future recommendations for others considering this approach.

\section{Method}

We briefly describe initial needs assessment work before outlining the design of the service and prospective service evaluation. The demographic and outcome data used was routinely collected within the NHS trust with relevant permissions gathered at time of hospital admission, so no additional permissions were needed and no personally identifiable data is reported. The initiation of the psychometric screening questionnaires and initial evaluation of the service were classed as 'service development activities' not requiring ethical approval within the hospital trust.

\section{Needs Assessment and Development}

To explore needs for the service and develop the business case, a needs assessment was conducted in 2012-2013. The IPS members identified patients they came into contact with, who they felt could potentially benefit from psychological support. This was because they either had history of pain for three or more months prior to admission, severe post-operative pain lasting beyond expected duration or accompanied by psychological distress, were patients with history of high dose opiate use and uncontrolled pain or pain of unknown origin lasting three or more months. They were invited to complete psychometric measures (see below) already used in the NHS Trust's chronic pain service, to help inform service needs. Among 15 patients completing the questionnaires, over $50 \%$ scored within the moderate/severe range on all four psychometric questionnaires. This information about unmet psychological need informed the business case and in October 2014 we were successful in employing a band 8c Psychologist, initially on a yearly rolling post, with built in obligation to conduct service evaluation.

In addition, an anonymous staff survey was given to the IPS $(n=7)$ regarding needs and priorities for the in-patient pain psychology service. Six staff members returned surveys: 3 medical consultants and 3 specialist pain nurses. All staff rated "brief CBT-based interventions" as a priority (100\%) followed by "psychological assessments of the most distressed patients" (83\%) and "staff training in brief interventions" (83\%). As a result, the psychologist role was designed to integrate with the existing IPS, with capacity to provide both brief and more extensive direct psychology input for patients struggling with pain-related distress, as well as wider support to the team such as providing staff training. The psychologist joined the team part time ( 7.5 hours per week), providing a) psychological assessment and brief psychological intervention for inpatients with pain-related distress, b) accompanying the IPS on ward rounds to offer multidisciplinary team advice and support, c) leading training and research activities as part of the IPS's remit, d) offering supervision to another band 8A psychologist joining the team from 2017 
for a 3.5 hour session a week, (initials removed for author anonymity) trainee psychologists and non-psychologist colleagues within the team.

\section{Service Evaluation}

A prospective service evaluation of the enhanced IPS was conducted to explore the impact of psychological intervention for samples of patients referred, in terms of patients' subsequent admissions and days in hospital over the 12 months after psychometric screening. We present comparative data from two samples of patients who had consented for direct psychological input, in a controlled before-and-after design. Those referred to as 'treatment group' patients were those referred to the psychologist for direct intervention between October 2014 and October 2017, completed the opt-in psychometric questionnaires and participated in at least one session with the psychologist. These patients were compared with a 'control group' of patients who completed screening but not intervention. This was because a) they completed their psychometric questionnaires as part of the 2012-2013 needs assessment when a service was not available, or b) they were referred to the service between 2014-2017 as with the treatment group, but were not able to receive psychological intervention. This was because they were unavailable at the time input could be delivered (such as being off the ward having an x-ray) or were discharged home or moved hospital before intervention could take place, or because of non-availability of the psychologist (e.g. during annual leave).

\section{Measures:}

From 2014 when the psychologist role was established, suitable patients for intervention were identified by the IPS during ward rounds if they presented with high levels of pain-related distress, had a history of chronic pain or repeated hospital admissions, as in the needs assessment phase. They were invited to complete the psychometric screening questionnaires (questionnaire used by the outpatient pain service in the trust) as an opt-in to seeing the pain psychologist. The following pain psychometric screening measures were completed by patients at screening, which were used to understand patient wellbeing characteristics and to help tailor assessment, formulations and interventions:

- Centre for Epidemiological Studies of Depression questionnaire (CES-D ${ }^{33}$ ) A 20-item valid and reliable measure of depression with a possible range of scores of 0-60, with higher scores indicating more depressive symptomatology.

- Pain Anxiety Symptom Scale Short Form 20 (PASS ${ }^{34}$ ), a 20-item valid and reliable measure of fear of pain with scores from 0-100.

- McGill Pain Questionnaire ${ }^{35}$ - The main component of the McGill pain questionnaire consists of 15 pain descriptors, first 11 being sensory descriptors and the last 4 sensory. Each of these are scored as none $=0$, mild $=1$, moderate $=2$, severe $=3$. The scale also includes a present pain intensity (no pain, mild, discomforting, distressing, horrible, excruciating) and visual analogue scale for pain.

- Numeric Rating Scale - 0-10 with 0 being "no pain" and 10 being "worst pain imaginable" This being the standard pain measure used in this hospital Trust.

- Roland Morris Disability Questionnaire ${ }^{36}$ A 24-item valid and reliable checklist of lower back pain related disability with scores from 0-24 with higher scores indicating higher disability. RMDQ was selected as it has been used extensively in studies of more widespread pain, and while many test items are back pain specific this is equally true for the intervention and control group. 
- Chronic Pain Acceptance Questionnaire ( $\mathrm{CPAQ}^{37}$ ) a 20-item valid and reliable measure assessing acceptance of chronic pain, with overall scores from 0-120 and two subscales: activity engagement $(0-66)$ and pain willingness $(0-54)$. Higher scores indicating higher pain acceptance, seen as facilitative to adjustment and coping.

The completed questionnaires were given by the IPS team members to the psychologist who attended patients at their bedside as soon as possible.

As part of routine service data collection, we collected demographic information on duration of pain, age, gender, work status and bodily location(s) of the pain experienced or self-reported diagnosed pain condition. We compared routinely collected data for the two groups regarding the number of subsequent hospital admissions and days of stay in hospital in the 12 months preceding psychological screening and 12 months immediately following psychological screening, as two key inpatient outcomes often used to evaluate the impact of hospital services and interventions.

\section{Analyses:}

Demographic and psychological screening data were analysed descriptively. Additionally, psychological screening data were compared between groups to explore any baseline differences between intervention and control groups, using parametric and non-parametric tests as per the data distribution. Cronbach's alpha was used to assess the internal consistency reliability within CES-D, PASS and RMDQ with $>.7$ taken as adequate consistency. Parametric statistics (paired sample $t$ tests and mixed-ANOVAS) were applied to compare number of admissions and hospital bed days between treatment and control groups over time. The withinsubjects independent variable was time-point (12 months up until psychological screening vs. 12 months following psychological screening with or without intervention); the between subjects independent variable was group (intervention or control group). Effect sizes were calculated as Hedges' g. P $<.05$ was used to denote statistical significance. We estimated potential cost savings based on general NHS information about hospital admissions, in which a nonelective inpatient admission is estimated at $£ 1603$ and each excess bed day estimated at $£ 346^{38}$.

\section{Results}

We were able to extract full data pre and post treatment for 64 patients included in this evaluation. Among those, 34 patients received psychological intervention (the treatment group) between October 2014-2017; 30 did not receive psychological intervention (the control group), including the 15 patients who completed the needs assessment in 2012-2013 and 15 patients screened during 2014-2017 as described above.

\section{Patient characteristics}

Table 1 illustrates key demographic characteristics of the 64 patients included in the evaluation. The majority of participants were women who were not currently employed; pain duration and participant ages ranged substantially. Those receiving psychological input reported pain in a range of bodily areas, most commonly abdominal pain $(n=19)$ and/or neck or back pain $(n=7)$ but also pain related to limbs/amputated stumps $(n=3)$, chest pain $(n=2)$, headaches $(n=1)$ and pain related to recurrent benign tumours $(n=1)$. Two reported diagnosed pain conditions, 
fibromyalgia and Rheumatoid Arthritis respectively. Control and treatment groups were similar in terms of mean age, gender split and pain duration. Cronbach alpha coefficients for psychometric measures were all above .7 suggesting they had internal consistency reliability.

Table 1: Patient characteristics

\begin{tabular}{|c|c|c|c|c|}
\hline $\begin{array}{l}\text { Descriptive } \\
\text { Statistics }\end{array}$ & $\begin{array}{lr}\begin{array}{l}\text { Duration } \\
\text { pain of } \\
\text { (range) }\end{array} & \text { years } \\
\end{array}$ & Age (range) & Gender & Work status \\
\hline Control $(n=30)$ & $(0.1-30)$ & $\begin{array}{l}38.34 \\
(19-63)\end{array}$ & $\begin{array}{l}21 \text { female }(70 \%) \\
9 \text { male }(30 \%)\end{array}$ & $\begin{array}{l}15 \text { unemployed } \\
6 \text { employed/self-employed } \\
4 \text { home makers } \\
2 \text { employed - off sick } \\
2 \text { retired } \\
1 \text { not specified }\end{array}$ \\
\hline $\begin{array}{l}\text { Intervention } \\
(n=34)\end{array}$ & $\begin{array}{l}5.0 \\
(0.1-43)\end{array}$ & $\begin{array}{l}35.14 \\
(18-80)\end{array}$ & $\begin{array}{l}29 \quad \text { female } \\
(85.3 \%) \\
5 \text { male }(14.7 \%)\end{array}$ & $\begin{array}{l}12 \text { unemployed } \\
10 \text { employed } \\
6 \text { students } \\
4 \text { employed - off sick } \\
2 \text { retired }\end{array}$ \\
\hline
\end{tabular}

\section{Psychological wellbeing at screening}

Analysis of completed psychometric screening questionnaires is included in table 2. This highlighted the clinical need for psychological input and appropriateness of referrals, as overall $39.3 \%$ of patients completing screening reported symptoms consistent with severe levels of depression; and $47.6 \%$ with severe pain-related anxiety. Pain-related disability was also prevalent and there were generally low scores for chronic pain acceptance. These scores were indicative of pain-related psychological distress.

Table 2: Psychological measures of treatment and control group at screening

\begin{tabular}{|l|l|l|}
\hline $\begin{array}{l}\text { Numbers } \\
\text { completing } \\
\text { measures }\end{array}$ & Control group & Treatment group \\
\hline $\begin{array}{l}\text { Depression } \\
\text { (CES-D scale) } \\
\text { Control n=27 } \\
\text { Treatment n=34 }\end{array}$ & $\begin{array}{l}\text { Mean 37.79 (range 5-54) } \\
(84.8 \% \text { Moderate or severe) }\end{array}$ & $\begin{array}{l}\text { Mean 33.79 (range 9-55) } \\
\text { (67.7\% Moderate or severe) }\end{array}$ \\
\hline $\begin{array}{l}\text { Pain-related } \\
\text { anxiety } \\
\text { (PASS scale) } \\
\text { Control n=29 } \\
\text { Treatment n=34 }\end{array}$ & $\begin{array}{l}\text { Mean 62.38 (range 10-96) } \\
\text { (82.8\% Moderate or severe) }\end{array}$ & $\begin{array}{l}\text { Mean 68 (range 42-100) } \\
\text { (82.4\% Moderate or severe) }\end{array}$ \\
\hline $\begin{array}{l}\text { McGill } \\
\text { Questionnaire } \\
\text { Control n=29 } \\
\text { Treatment n=33 }\end{array}$ & $\begin{array}{l}\text { Sensory mean 19.94 (range 3-33) } \\
\text { Affective mean 7.36 (range 0-12) }\end{array}$ & $\begin{array}{l}\text { Sensory mean 16.86 (range 6-28) } \\
\text { Affective mean 7.52 (range 2-12) }\end{array}$ \\
\hline
\end{tabular}




\begin{tabular}{|l|l|l|}
\hline & & \\
\hline $\begin{array}{l}\text { Pain Numeric } \\
\text { Rating Scale } \\
\text { (pain now) }\end{array}$ & $\begin{array}{l}\text { Mean 7.51 (range 4-10) } \\
\text { Nontrol n=29 } \\
\text { Cont10 gave scores of 9 or } \\
\text { Treatment n=34 }\end{array}$ & $\begin{array}{l}\text { Mean 7.44 (range 3-10) } \\
\text { N=9 (26\%) gave scores of 9 or 10/10 }\end{array}$ \\
\hline $\begin{array}{l}\text { Pain-related } \\
\text { disability } \\
\text { (RMDQ) } \\
\begin{array}{l}\text { Control n=30 } \\
\text { Treatment n=34 }\end{array}\end{array}$ & $\begin{array}{l}\text { Mean 19.63 (range 7-24) } \\
\text { (86.6\% Moderate or severe) }\end{array}$ & $\begin{array}{l}\text { Mean 18.94 (range 8-24) } \\
\text { (83.5\% Moderate or severe) }\end{array}$ \\
\hline $\begin{array}{l}\text { Chronic Pain } \\
\text { Acceptance } \\
\text { (CPAQ) } \\
\text { Control n=28 } \\
\text { Treatment n=23 }\end{array}$ & Overall mean 38.75 (range 6-87) & Overall mean 44.49 (range 5-105) \\
\hline
\end{tabular}

CES-D and PASS scores were normally distributed and met parametric testing assumptions. Independent samples $t$ tests comparing mean group scores for CES-D and PASS confirmed that baseline scores did not differ significantly between the intervention and control groups [CES$\mathrm{D} t(59)=-1.082, p=.284]$, [PASS $t(61)=-1.076, p=.286]$. The RMDQ scores were examined using non-parametric tests as there was a significant negative skew. For the RMDQ scores an independent samples median test confirmed that the medians of the scores on the RMDQ at baseline were also not significantly different between groups at baseline [ $p=.627]$, suggesting the groups were comparable in terms of psychological distress and pain-related disability before intervention.

\section{Psychological interventions}

Among the 34 patients within treatment group, the mean contact time was 135 minutes and the modal time 90 minutes (range 10-960 minutes, see figure 1). Interventions were delivered in between 1 and 11 sessions; the mode number of sessions was 1 and 21 patients $(70 \%)$ received either 1 or 2 sessions. The majority of interventions (25 patients, 74\%) lasted 2 hours or fewer in total, with only $8.82 \%$ of interventions (3 patients) requiring more extensive psychological intervention lasting more than 3 hours in total, as shown in figure 1. Thus, the majority of patients received less than two hours of psychological intervention during their inpatient stay. This was usually delivered as one contact and formed initial screening assessment, formulation and brief intervention within that one contact session.

Interventions were mostly based on CBT and focussed on identifying catastrophic beliefs, with individual formulations to understand the unintentional consequences of increased arousal, hypervigilance and avoidant pain behaviours. Bedside self-management strategies included 
psychoeducation, behavioural techniques (e.g. breathing and relaxation exercises) and cognitive strategies to learn new ways of thinking about their pain and its impact upon themselves. Some acceptance-based interventions were applied to support chronic pain acceptance, driven by the formulation. Three example case studies are presented in figure 2, to illustrate three types of input, from brief biopsychosocial formulation and CBT strategies, to formulation and referral to outpatient pain centre follow-up to a more intensive intervention.

In addition to direct therapeutic interventions, as planned the psychologist carried out a variety of other activities as a member of the IPS. These included offering psychological formulations and advice to other IPS members, and providing clinical supervision to a second psychologist (initials removed for author anonymity) who also joined the team part time and to trainee psychologists conducting research. The psychologist also delivered indirect psychological interventions, sharing formulations with medical teams to help them to understand pain-related distress as a "normal" response to pain rather than being viewed in a dualistic manner and seeing complex pain as 'emotional' in nature. This was achieved by attending multidisciplinary meetings and delivering formal pain psychology teaching sessions on the ward. She was also actively involved in audit and research activities related to other pain related projects within the pain team.

Figure 1: Psychologist contact time with patients in the treatment group $(n=34)$.

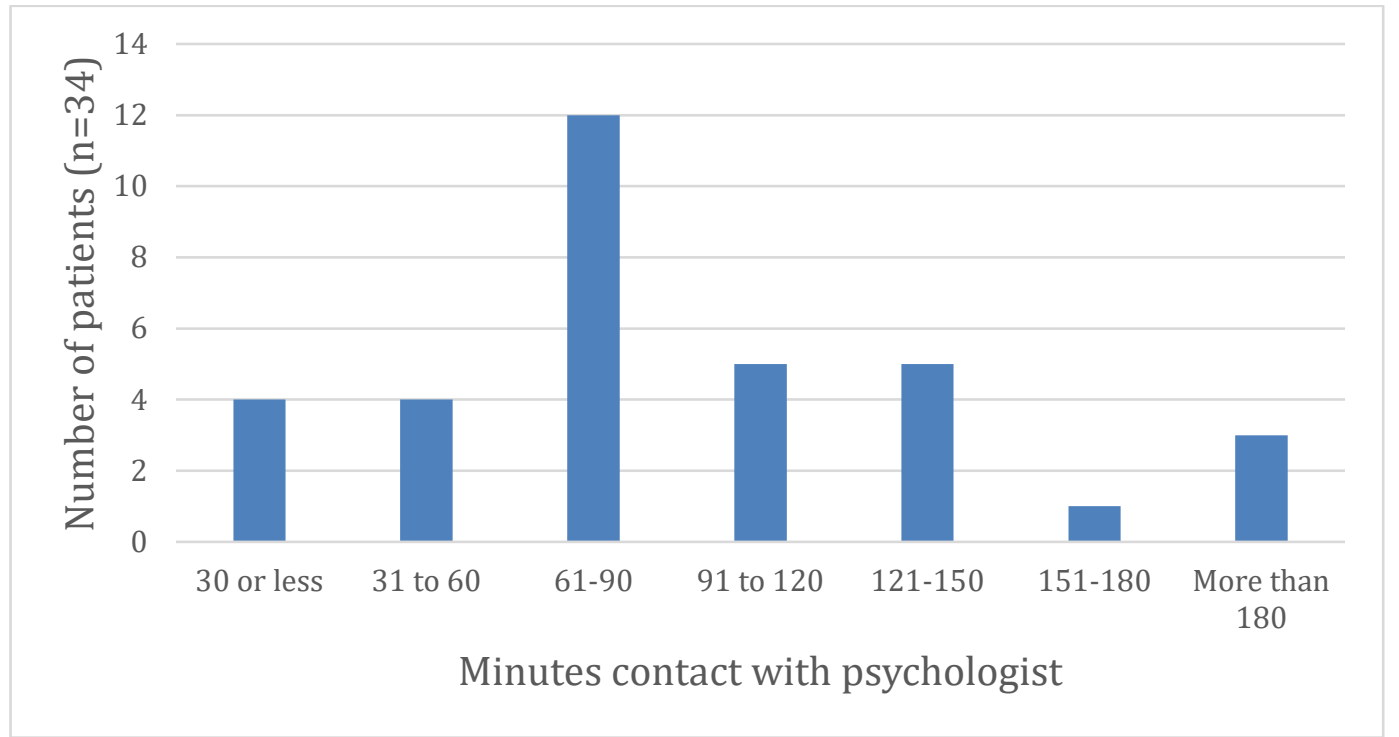

Figure 2: Case studies

Case X: Example brief psychological intervention:

$\mathrm{X}$ was 42 -year-old teacher with a 10 -month history of abdominal pain. She had been admitted under gastroenterology with severe abdominal pain and was expecting surgery to resolve her pain. She had a past medical history of Fibromyalgia, migraine and chronic fatigue syndrome. She was investigated extensively but no cause was found for her abdominal pain. Her screening questionnaires suggested severe pain-related disability (RMDQ 23/24) severe painrelated anxiety (PAS 63/100) and severe depression (CESD 42/60). Whilst initially reluctant to consider psychologically based pain management, a joint consultation with her Consultant 
Gastroenterologist and psychologist explained that all sinister causes had been ruled out and that self-management strategies were the most effective way to get home to her family. X then engaged well in 150 minutes of bedside brief pain psychology intervention. This involved further pain education, the circular relationship between stress and pain and the rational for behavioural stress reduction techniques. Cognitive strategies were also practiced, such as recognising catastrophic thoughts about sinister causes for her pain, practicing thought challenging strategies to ask herself "what evidence do I have that I am dying" and finally focusing on the future by considering realistic family goals that could be achieved by pacing or adapting activities. X reported feeling much calmer and more in control of her pain following this one extended session of pain psychology. She was given information booklets to support the discussion and the breathing and relaxation exercises were recorded on her mobile phone to support regular practice.

$\mathrm{X}$ had 3 admissions in the 12 months' pre-treatment, (mean duration $=16$ days). Treatment was 150 minutes assessment and brief intervention, in one session. Post-treatment, $\mathrm{X}$ had 1 admission (in 12 months) $=2$ days, thus, an $87.5 \%$ reduction in length of admission.

\section{Case: Y: Example of intensive pain psychology therapy alongside medical intervention:}

Y was a 30-year-old lady living with benign tumors in her abdominal wall. Y was undergoing frequent radiofrequency ablation treatment. Before intervention, Y had experienced 32 previous hospital admissions and spent 567 days in hospital (mean 22.68 days per admission). Unfortunately, over the course of the previous 12 months, Y had become more hopeless and distressed and had started to employ passive avoidant dependent coping strategies (taking excessive rest, increasing doses of opioids, avoiding mobilising whilst in hospital and reliance upon staff for self-care). Ward team members began to perceive $Y$ as a 'demanding patient', and her frequent and insistent requests for pain medication led to deteriorations in the patient-provider relationship.

Y was repeatedly visited by the IPS, who recognised her distress and pain behaviours and referred her for psychological input. Her screening questionnaires indicated severe painrelated disability (RMDQ 24/24) severe pain-related anxiety (PASS 72/100) and moderatedepression (CESD 38/60).

Following assessment, a psychologist offered her 16 hours of psychological assessment and intensive therapy (11 therapy sessions in total). This was Cognitive Behavioural Therapy (CBT) and psychologically-based pain rehabilitation, including:

- Psycho-education explaining the difference between acute and chronic pain, when hurt does not always mean harm,

- Neurobiology of the bodily stress response, behavioural stress management strategies (diaphragmatic breathing and relaxation techniques)

- Cognitive strategies: recognising and challenging negative thoughts, problem formulations, role of safety and avoidance in maintaining problems,

- $\quad$ Problem solving, setting goals and maintaining change

- Mindfulness, acceptance and additional compassion-based techniques

Post treatment, Y reported that she felt much calmer and more able communicate effectively with her consultants, negotiate treatment options, and to manage independently at home. In the 12 months' pre-treatment $Y$ had two admissions (199 bed days, mean 99.5 days per admission). Both were deemed by the surgeons to be unnecessarily long stays, mainly due to 
Y's inability to cope with the pain and very high doses of analgesics including opiates and the consequent side-effects.

In the 12 months' Post-treatment, $\mathrm{Y}$ had 3 further admissions for radiofrequency ablation. During these admissions communication between the surgical team and Y was improved, and Y felt able to work with the IPS, in trying different strategies to control pain including, short duration Ketamine infusion and opiate reduction. Her ability to cope with acute exacerbations were enhanced using the psychological strategies learnt. Her three admissions for radio frequency ablation post-intervention totalled 58 bed days, (mean 19.33 days per admission) but each stay was progressively shorter than the last, with 141 fewer bed days compared to 12 months pre-treatment.

\section{Case Z: Example of signposting onto Pain Management Programme}

Z was 26-year-old staff nurse with an 18-month history of Fibromyalgia. She had been admitted under Rheumatology with an exacerbation of her chronic widespread pain. All investigations had proven normal and screening questionnaires suggested severe painrelated disability (RMDQ 21/24) severe pain-related (PASS 71/100) and severe depression (CESD 45/60).

$\mathrm{Z}$ engaged well in a brief bedside pain psychology intervention of 120 minutes. This included psychoeducation and reassurance that this episode of increased pain was a flare-up and could be managed with psychologically based pain management strategies. She was trained in simple behavioural stress reduction techniques (breathing and relaxation exercises) She was then signposted onto a Pain Management Programme as an outpatient. $\mathrm{Z}$ had 2 admissions for flare-ups in the 12 months' pre-treatment, ( 7 bed days) and no subsequent admissions posttreatment.

\section{Treatment effects}

\section{Hospital admissions}

Comparing the 12 months before psychological screening and the 12 months following this, total hospital admissions reduced by $59.7 \%$ in the treatment group (from a total of 92 to 37) but slightly increased by $7 \%$ in the control group (from a total of 83 to 89). Table 3 shows the mean, standard deviation and range in hospital admissions.

A mixed ANOVA exploring these data statistically found a significant interaction effect for group and time-point $[\mathrm{F}(1,62)=7.21, \mathrm{p}=.009]$. Paired samples t-tests confirmed that the reduction in hospital admissions over time was statistically significant for the treatment group [ $\mathrm{t}(33)=4.34$, $\mathrm{p}<.001$; but there was no significant change for the control group [ $\mathrm{t}(29)=-.342, \mathrm{p}=.735]$. Hedges $\mathrm{g}$ was calculated as 0.60 , denoting a medium intervention effect size. Figure 2 compares mean hospital admissions 12 months before and 12 months following psychological screening.

Table 3: Mean, standard deviation and range of hospital admissions and bed days in the 12 months prior to and following intervention 


\begin{tabular}{|l|l|l|l|l|l|}
\hline Group & & \multicolumn{3}{|l|}{ Hospital admissions } & \multicolumn{2}{l|}{ Hospital bed days } \\
\hline & & Pre & Post & Pre & Post \\
\hline Treatment & Mean & 2.71 & 1.09 & 44.59 & 7.18 \\
& SD & 2.30 & 1.83 & 43.05 & 14.85 \\
& Range & $(1-9)$ & $(0-6)$ & $(4-199)$ & $(0-58)$ \\
\hline Control & Mean & 2.77 & 2.97 & 29.77 & 17.53 \\
& SD & 2.49 & 4.17 & 31.19 & 32.59 \\
& Range & $(1-10)$ & $(0-22)$ & $(1-113)$ & $(0-171)$ \\
\hline
\end{tabular}

Figure 2:

Mean hospital admissions 12 months before and following psychological screening

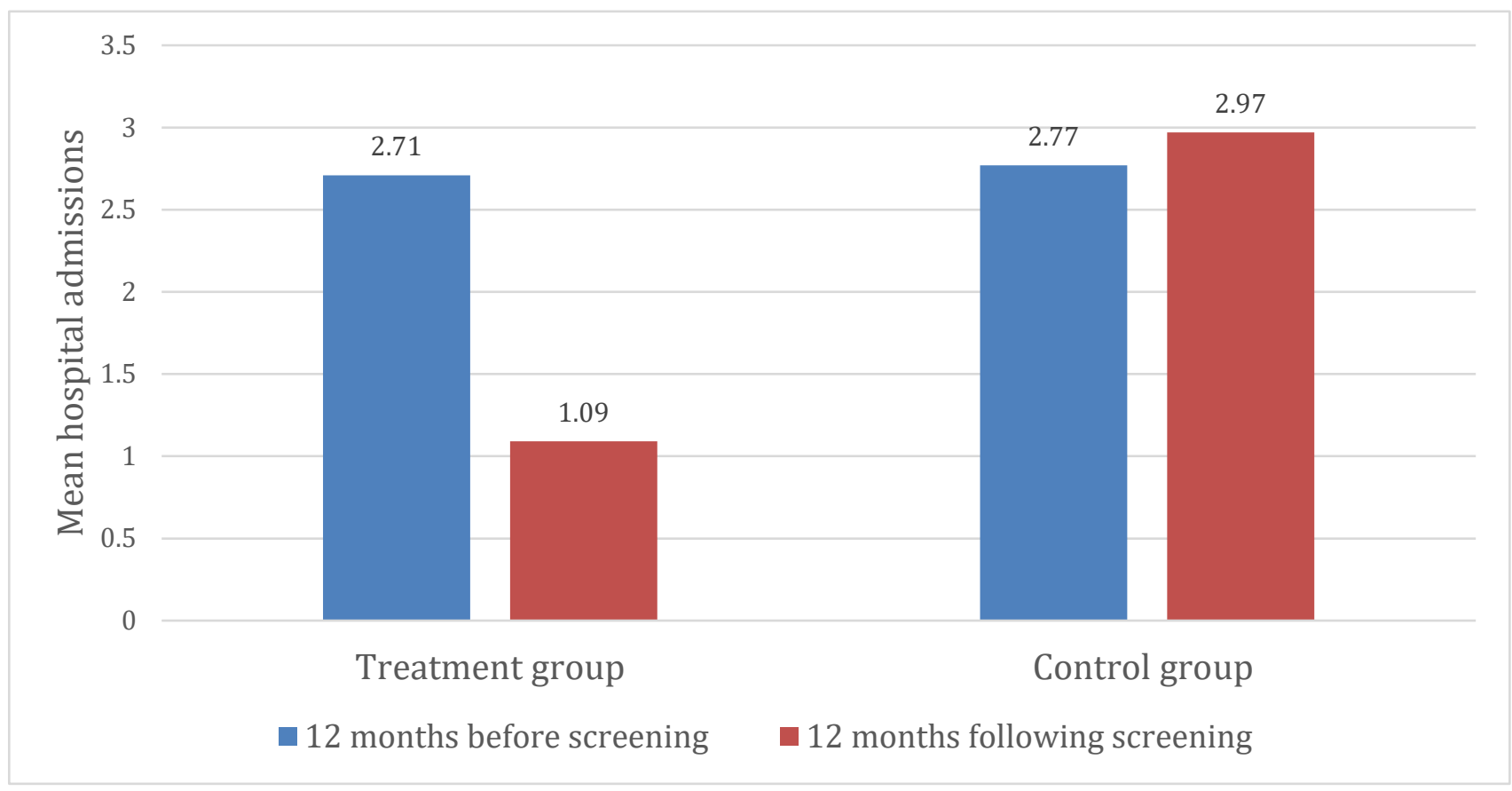

Table 3 shows the mean, standard deviation and range in days of stay. The mixed ANOVA for these data also found a significant interaction effect for group and time point $[F(1,62)=8.90$, $\mathrm{p}=.004]$, so that bed days for the treatment group reduced significantly more $[\mathrm{t}(33)=5.95$, $\mathrm{p}<.001]$ than for the control group [ $\mathrm{t}(29)=2.23, \mathrm{p}=.034]$. Hedges' $\mathrm{g}$ was calculated at 0.42, denoting a small to medium effect size. Figure 3 compares mean days of stay in hospital 12 months before and following psychological screening.

Figure 3: Mean days of stay in hospital 12 months before and following psychological screening

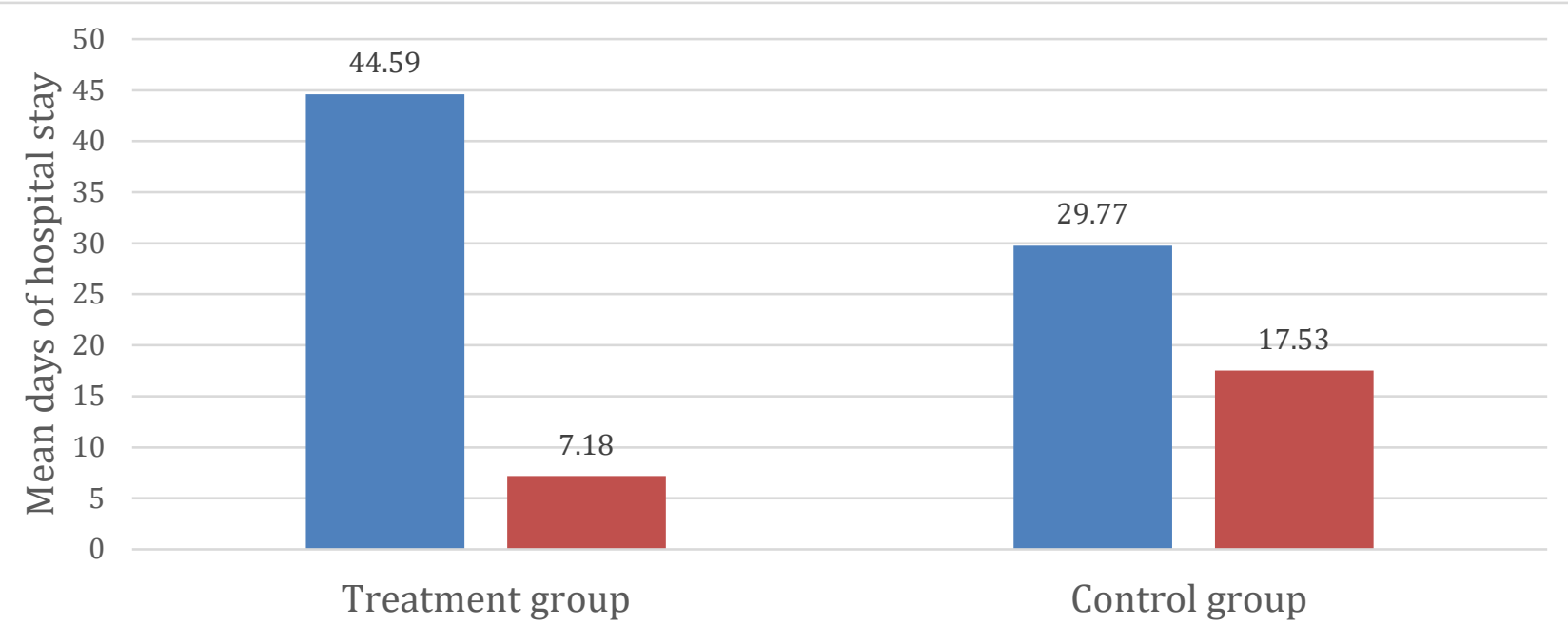


Overall, the treatment group experienced a total of 55 fewer admissions and 1274 bed days than the control group in the 12 months following treatment. Using generic NHS figures for admission and excess bed day $\operatorname{costs}^{38}$, this equates to a potential difference in inpatient treatment costs of $£ 528,969$ ( $55 \times £ 1603$ admissions; $1274 \times £ 346$ excess bed days).

\section{Discussion}

This article describes the development of a pain psychologist role within an adult Inpatient Pain Service (IPS) in a large NHS Trust in the North West of England. The role of the psychologist in management of outpatient chronic pain has been well-documented ${ }^{14}$ but is less commonly implemented or evaluated in the IPS context ${ }^{32}$. We presented the needs assessment, development and initial service evaluation of a psychologist's role within an IPS. Nonpsychologists within the IPS were able to identify and refer those who could benefit from direct psychological intervention, as demonstrated by the high levels of pain-related distress in the sample presented. The pain psychologist successfully engaged patients in ward-based interventions largely based around CBT; encouraging a more biopsychosocial understanding of acute and chronic pain. Psychological input was formulation driven and typically focussed on reducing distress and enhancing coping and self-management strategies for pain, reducing reliance on medication and enhancing adherence to medical advice. This drew on evidencebased psychological approaches to offer cognitive and behavioural self-management techniques, ${ }^{14}$ often included in chronic Pain Management Programmes (PMPs) ${ }^{7}$. This suggests that these outpatient PMP skills can be successfully adapted to be largely delivered as brief psychological interventions on the ward in less than two hours to fit in with admission durations. However, the psychologist worked flexibly, offering more complex patients outpatient followup if needed, in this way similar to the coordinated approach advocated by Katz et al. ${ }^{24}$. As described, the psychologist also offered interventions to the IPS and other medical teams to support their work with patients struggling with pain in hospital, achieving a balance of 'direct' and 'indirect' clinical activity 39 .

Initial service evaluation suggested a 59.7\% decrease in hospital admissions and 84\% drop in mean hospital stay in the 12 months following psychological intervention, significantly lower than experienced by a control group who completed psychological screening but not intervention. The cost-saving estimates reported, (though estimates from general NHS data and relying on assumptions that costs for these patients were similar) suggest that adding a psychologist to IPSs may have potential to reap substantial cost-savings as well as representing best practice. Our study affirms the conclusions of the small case series published by Childs et.al. ${ }^{32}$ who concluded "through reduced length of stay and avoidance of unnecessary readmission, psychologists may prove both cost-effective as well as able to improve both quality of life and overall clinical outcomes for inpatients." (p.2296). More importantly still might be the wellbeing benefits patients may experience through reduced unnecessary time in hospital away from their normal coping resources. Our study therefore extends the conclusions of others proposing the benefits of psychology within multi-disciplinary pain teams ${ }^{24,40}$.

\section{Challenges and learning}

Several challenges and areas of learning emerged during this initial phase of the service. Firstly, anecdotally we experienced that the intervention had to be matched to the patient's current readiness to change ${ }^{41}$. Some patients found it very difficult to consider psychological self- 
management approaches when they were highly distressed, and chose not to complete the 'optin' screening questionnaires. Other patients had experienced iatrogenic distress from multiple conflicting opinions delivered by hospital staff, and this was a barrier to engaging with a psychological approach, as found in previous studies ${ }^{42}$. Most notably, we experienced that some patients reported being told that their pain was "all in your head'. This may have caused an "inoculation effect' that made them even more determined to seek further biomedical treatment. It may help for pain psychologists to attend ward rounds and meetings with referring medical teams, to enhance non-specialists' understanding of pain-related distress and so improve patient-provider communication around pain. However, the size of the NHS trust and availability of the pain psychologist limited opportunities for such indirect interventions.

In terms of limitations of this study, it was not possible to reliably collect psychological screening measures at two time points, largely because of the unpredictable timings of discharge. This limits our understanding in what ways, if at all, the mostly brief psychological interventions may have improved patients' symptoms of depression and pain-related anxiety, as well as any impacts on pain, disability and pain acceptance. The controlled before-and-after study design of our health economic data analysis was a practical and ethical design for this real-world evaluation, but does carry risk of bias. Control and intervention group patients scored similarly on psychological measures and shared similar demographic characteristics but their unavailability for psychological contact may have indicated another reason such as greater medical complications or disinterest in health professional contact which may have precipitated the differences in admissions and bed days seen following this. However, this is unlikely since all patients included had opted into seeing a psychologist, and a key reason for lack of availability was early discharge indicating medical fitness. The control group patients who were also part of the needs assessment were included before October 2014 when the psychologist began in post. Perhaps routine hospital care changed in this time, so that these patient data differed in some ways from later control or treatment group patient data. A final limitation was in terms of availability and accuracy of data. The complexity of extracting health economic data meant that we only included a sample of 64 patients who had completed 12 months post treatment in this pragmatic service evaluation, other patients without complete data were not included.

In future, it would be useful to collect post-treatment psychological outcome measures to be able to more fully demonstrate effectiveness of psychological input, and potentially scale up this work to incorporate other intervention and control sites, as recommended by cochrane ${ }^{43}$. While anecdotally we can see the benefit with in the team, we have not formally evaluated the value of indirect psychological input, such as the training offered to undergraduate and postqualification professionals in enhancing their psychologically informed practice of pain management.

\section{Conclusions}

Developing a role for a psychologist took several years, from initial needs assessment to a part time post being developed, but initial service evaluations of a sample of direct patient work suggest this may impact on hospital admissions and length of stay. We also have no doubt that the introduction of a pain psychologist into the Inpatient Pain Service has changed the way the team functions. This includes enhancement of psychologically informed practice of team members, who have been empowered to recognise psychological distress, communicate more effectively with distressed patients and possibly set them on the path from pre-contemplative to 
contemplative stages of change ${ }^{41}$. Anecdotally, IPS team members report that as a result of informal and formal teaching and training by the psychologist with other IPS team members, the quality of referrals to the IPS have improved, with better understanding from the parent referring teams as to what the inpatient pain service can offer.

The pain psychologist post ( 0.2 WTE) has been made permanent in IPS and it is now difficult to envision an inpatient pain service without access to a pain psychologist. One of the main barriers to offering consistent service is availability of psychologist, with flexibility to match the availability of patients in the dynamic acute care setting, so we would recommend teams hoping to develop such a role consider developing a full time post, depending on service requirements. In conclusion, psychologists can become valuable members of the team offering direct and indirect input to enhance the work of the IPS, enabling the true multidisciplinary approach including psychological expertise as originally recommended at their inception ${ }^{10}$.

\section{References}

1. Breivik H, Collett B, Ventafridda V, et al. Survey of chronic pain in Europe: prevalence, impact on daily life, and treatment. Eur J Pain 2006;10(4):287-287.

2. Cordell WH, Keene KK, Giles BK, et al. The high prevalence of pain in emergency medical care. The Am J Emerg Med; 2002; 20(3):165-9.

3. Sawyer J, Haslam L, Daines P, et al. Pain prevalence study in a large Canadian teaching hospital. Round 2: lessons learned? Pain Man Nursing. 2010; 11(1):45-55.

4. Rockett MP, Simpson G, Crossley R, et al. Characteristics of pain in hospitalized medical patients, surgical patients, and outpatients attending a pain management centre. $\mathrm{Br} \mathrm{J}$ Anaesth. 2013;110(6):1017-23.

5. Faculty of Pain Medicine of the Royal College of Anaesthetists (RCOA). Core standards for pain management services in the UK. London: RCOA, 2015.

6. Brennan F, Carr DB, Cousins M. Pain management: a fundamental human right. Anesth Analg. 2007;105(1):205-21.

7. Baratta JL, Schwenk ES, Viscusi ER. Clinical consequences of inadequate pain relief: barriers to optimal pain management. Plastic and recon surg. 2014; 1;134(4S-2):15S-21S.

8. Ramsay MA. Acute postoperative pain management. In Baylor University medical center proceedings. 2000; 13 (3): 244-247.

9. Ready LB, Oden R, Chadwick HS, et al. Development of an anesthesiology-based postoperative pain management service. Anesthesiology, 1988;68(1):100-6.

10. Royal college of surgeons of England (RCOS), College of anaesthetists (RCOA). Report of the working party on pain after surgery. 1990; London: RCOS/RCOA.

11. Ossipov MH, Dussor GO, and Porreca F. Central modulation of pain. J Clin Invest, 2010;120(11), 3779-3787.

12. Katz J, Seltzer Z. Transition from acute to chronic postsurgical pain: risk factors and protective factors. Expert Rev Neurother, 2009;9(5): 723-744.

13. Salkovskis PM. Psychological treatment of noncardiac chest pain: the cognitive approach. The American journal of medicine. 1992 May 27;92(5):S114-21.

14. Williams, Eccleston and Morley. Psychological therapies for the management of chronic pain (excluding headache) in adults. Cochrane Database Syst Rev, 2012;11:CD007407. doi:10.1002/14651858.CD007407.pub3.

15. Feliu-Soler A, Montesinos F, Gutierrez-Martinez O, Scott W, McCracken LM, Luciano JV Current status of acceptance and commitment therapy for chronic pain: a narrative 
review. J Pain Res. 2018; 2 (11) 2145-2159

16. Gilpin HR, Stahl DR, and McCracken LM A Theoretically guided approach to identifying predictors of treatment outcome in Contextual Cognitive Behavioural Therapy for chronic pain European Journal of Pain 2019; 23(2) 354-366

17. Morasco, B. J., Lovejoy, T. I., Lu, M., et al. The relationship between PTSD and chronic pain: mediating role of coping strategies and depression. Pain, 2013; 154(4), 609-616.

18. Vlaeyen, JW, and Linton, S.J. Fear-avoidance model of chronic musculoskeletal pain: 12 years on. Pain, 2012; 153(6), 1144-1147.

19. Alattas, SA, Smith, T, Bhatti, M, et al. Greater pre-operative anxiety, pain and poorer function predict a worse outcome of a total knee arthroplasty. Knee Surg Sports Traumatol Arthrosc . 2017; 25(11): pp.3403-3410.

20. Levett, DZH, and Grimmett, C. Psychological factors, prehabilitation and surgical outcomes: evidence and future directions. Anaesthesia, 2019; 74: pp.36-42.

21. Ip HY, Abrishami A, Peng PW, et al. Predictors of postoperative pain and analgesic consumption: a qualitative systematic review. Anesthesiology, 2009;111(3):657-677.

22. Kerper LF, Spies CD, Buspavanich P, Balzer F, Salz AL, Tafelski S, Lau A, Weiß-Gerlach E, Neumann T, Glaesmer H, Wernecke KD. Preoperative depression and hospital length of stay in surgical patients. Minerva Anestesiol. 2014;1;80(9):984-1.

23. Grady K, Jalowiec A, White-Williams C. Preoperative psychosocial predictors of hospital length of stay after heart transplantation. Journal of Cardiovascular Nursing. 1999 Oct $1 ; 14(1): 12-26$.

24. Katz J, Weinrib A, Fashler S et al. The Toronto General Hospital Transitional Pain Service: development and implementation of a multidisciplinary program to prevent chronic postsurgical pain. J Pain Res, 2015; 8: 695-702.

25. Bernard A, Wright S. Chronic pain in the Emergency Department. Am J Emerg Med 2004;22(6):444-7.

26. McLeod D, and Nelson K. The role of the emergency department in the acute management of chronic or recurrent pain. Australas Emerg Nurs J, 2013; 16(1): 30-36.

27. Wheeler DW, Kinna S, Bell A, et al. Hospitalization due to acute exacerbation of chronic pain: an intervention study in a university hospital. Scand. J. Pain 2017; 17(1): 345-349.

28. British Pain Society (BPS). Guidelines for Pain Management Programmes for adults: An evidence-based review prepared on behalf of the British Pain Society. London: BPS, 2013.

29. Royal College of Anaesthetists (RCOA). Guidelines for the provision of anaesthetic services (GPAS). Chapter 11: Guidelines for the Provision of Anaesthesia Services for Inpatient Pain Management 2019. London: RCOA, 2019.

30. Faculty of Pain Medicine of the Royal College of Anaesthetists (RCOA). Core standards for pain management services in the UK. 2015, London: RCOA.

31. Rockett M, Vanstone R, Chand J, et al. A survey of acute pain services in the UK. Anaesthesia, 2017; 72: 1237-42

32. Childs SR, Casely EM, Kuehler BM et al. The clinical psychologist and the management of inpatient pain: a small case series. Neuropsychiatr Dis Treat 2014; 10: 2291-7.

33. Radloff LS. The CES-D scale: a self-report depression scale for research in the general population. Appl Psychol Meas, 1977; 1: 385-401.

34. McCracken LM, Zayfert C, and Gross RT. The Pain Anxiety Symptoms Scale: development and validation of a scale to measure fear of pain. Pain 1992; 50(1): 67-73.

35. Melzack R. The McGill Pain Questionnaire: major properties and scoring methods. Pain 1975; 1 (3): 277-299. 
36. Roland MO, and Morris RW. A study of the natural history of back pain. Part 1: development of a reliable and sensitive measure of disability in low back pain. Spine 1983; 8: 141-144.

37. McCracken LM, Vowles KE, and Eccleston C. Acceptance of chronic pain: component analysis and a revised assessment method. Pain 2004; 107(1-2): 159-66.

38. NHS Improvement. Reference costs 2017/18: highlights, analysis and introduction to the data. London: NHS Improvement, 2018.

39. British Psychological Society. Guidelines on activity for clinical psychologists. 2012 Accessed from https://www.bps.org.uk/sites/www.bps.org.uk/files/Member\%20Networks/Divisions /DCP/Guidelines\%20of\%20Activity\%20for\%20CP\%27s.pdf

40. Giusti EM, Pietrabissa G, Manzoni GM, Cattivelli R, Molinari E, Trompetter HR, Schreurs $\mathrm{KM}$, Castelnuovo G. The economic utility of clinical psychology in the multidisciplinary management of pain. Frontiers in psych. 2017; 31;8:1860.

41. Prochaska JO and DiClemente CC. Stages and processes of self-change of smoking: Toward an integrative model of change. J Consult Clin Psychol, 1983; 51(3): 390-395.

42. Frantsve LM and Kerns RD. Patient-provider interactions in the management of chronic pain: current findings within the context of shared medical decision-making. Pain medicine. 2007; 1;8(1):25-35.

43. Cochrane effective practice and organisation of care group. What study designs can be considered for inclusion in an EPOC review and what should they be called? Accessed from:

https://epoc.cochrane.org/sites/epoc.cochrane.org/files/public/uploads/Resourcesfor-authors $2017 /$ what study designs should be included in an epoc review.pdf 